\title{
HO-1/EBP interaction alleviates cholesterol-induced hypoxia through the activation of the AKT and Nrf2/mTOR pathways and inhibition of carbohydrate metabolism in cardiomyocytes
}

\author{
XIAOHAN JIN ${ }^{1,2 *}$, ZHONGWEI XU ${ }^{2 *}$, JIN CAO $^{3}$, RUI YAN ${ }^{2}$, RUICHENG XU ${ }^{3}$, RUIQIONG RAN ${ }^{1}$, \\ YONGQIANG MA ${ }^{1}$, WEI CAI ${ }^{1}$, RONG FAN $^{2}$, YAN ZHANG ${ }^{2}$, XIN ZHOU $^{1}$ and YUMING LI ${ }^{1}$ \\ ${ }^{1}$ Tianjin Key Laboratory of Cardiovascular Remodeling and Target Organ Injury, Tianjin 300162; ${ }^{2}$ Central Laboratory, \\ ${ }^{3}$ Department of Basic Medicine, Logistics University of the Chinese People's Armed Police Force, Tianjin 300309, P.R. China
}

Received June 28, 2016; Accepted May 3, 2017

DOI: $10.3892 /$ ijmm.2017.2979

\begin{abstract}
Heme oxygenase-1 (HO-1) is an inducible and cytoprotective enzyme that provides a defense against oxidant damage. The present study screened 137 HO-1/interacting proteins using a profound co-immunoprecipitation (Co-IP) coupled with proteomics, and profiled the global HO-1 interactome network, including oxidative phosphorylation, endoplasmic reticulum and transport vesicle functions. Among these molecules, we observed that a novel interactor, emopamil-binding protein (EBP), is closely related to the cholesterol metabolism process. This study demonstrated that cholesterol promotes excessive oxidative stress and alters the energy metabolism in cardiomyocytes, further triggering numerous cardiovascular diseases. We observed that cholesterol caused the overexpression of EBP and HO-1 by the activation of AKT and Nrf2/mTOR pathways. In addition, HO-1 and EBP performed a myocardial protective function. The overexpression of HO-1 alleviated the cholesterol-induced excessive oxidative stress status by inhibition of the carbohydrate metabolism. Notably, we also confirmed that the loss of partial HO-1 activity aggravated the oxidative damage and cardiac systolic function induced by a high-fat diet in HO-1 heterozygous $\left(\mathrm{HO}^{-1+}\right)$ mice. These findings indicate that the HO-1/EBP interaction plays a protective role in alleviating the dysfunction of oxidative stress and cardiac systolic function induced by cholesterol stimulation.
\end{abstract}

Correspondence to: Professor Yuming Li or Dr Xin Zhou, Tianjin Key Laboratory of Cardiovascular Remodeling and Target Organ Injury, Tianjin 300162, P.R. China

E-mail: cardiolab@live.com

E-mail: xzhou@live.com

${ }^{*}$ Contributed equally

Key words: heme oxygenase-1, emopamil-binding protein, proteomics, cholesterol, hypoxia

\section{Introduction}

The heme-heme oxygenase (HO) system is comprised of constitutive HO-2 and inducible HO-1 isoforms, which play a key role in defense mechanisms against a series of external stimuli, including cytokines, oxidants, hypoxia and pharmacological agents $(1,2)$. HO-1 is a rapidly inducible stress-responsive enzyme that degrades heme to carbon monoxide (CO), biliverdin and ferrous iron (3). Induction of HO-1 provides a protective function in the cardiovascular system through the effects of $\mathrm{CO}$ and bilirubin on various cells. HO-1 executes anti-apoptotic, anti-inflammatory, anti-hypertensive and antioxidant functions, and protects the cardiovascular system by the activation of the p55/TNFR-1, p38 MAPK and PI3K/AKT signaling pathways (4-6). Importantly, the HO-1 gene promoter sequence contains a large quantity of regulatory cis-elements, such as stress-responsive, hypoxia-responsive, and cadmium responsive elements and NF- $\mathrm{KB}$ binding sites (7-9). Obesity is a risk factor leading to heart disease, including an increase in the incidence of cardiac diseases such as coronary artery disease, heart failure and cardiomyopathy (10-12). Metabolic syndrome induced by excessive intake of cholesterol is a pathological condition. A long-term high-fat diet results in systemic inflammation and oxidative stress. The risk factor induces the disruption of metabolic homeostasis and promotes progressive cardiovascular dysfunction $(13,14)$. HO-1 overexpression in macrophages can significantly improve the function of adipose cells and enhance insulin sensitivity. Meanwhile, HO-1 upregulation in the failing heart is a cardioprotective adaptation for improving left ventricular (LV) function.

Clinical studies have shown that a long-term high-fat diet may be a critical factor in the occurrence and progression of a series of cardiovascular diseases, including hypertension, coronary atherosclerosis and heart failure. However, the protective mechanism underlying how HO-1 antagonizes the excessive intake of cholesterol is still obscure. The aim of the present study was to elucidate the mechanisms of the anti-oxidative damage effects of HO-1 against the cholesterol stimulation condition.

Here, we first demonstrated that 137 HO-1 interactive proteins, especially a novel interactor emopamil-binding 
protein (EBP), may influence the intracellular lipid metabolism. We constructed an HO-1 interactive network using bioinformatic analysis. We also confirmed that cholesterol stimulation could induce myocardial hypoxia, activate the PI3K/AKT and nuclear factor erythroid 2-like 2 (Nrf2)/mTOR signaling pathways, and subsequently upregulate the expression of HO-1, binding the increasing number of EBP to restore the balance of intracellular lipid metabolism and cardiomyocyte function in in vivo and in vitro experiments.

\section{Materials and methods}

Materials. High-glucose Dulbecco's modified Eagle's medium (H-DMEM) was obtained from Basalmedia Technologies (Shanghai, China) and fetal bovine serum (FBS) was obtained from Bailing Biotechnology (Lanzhou, China). TurboFect ${ }^{\mathrm{TM}}$ transfection reagent (R0531) and Pierce ${ }^{\mathrm{TM}}$ Protein G Magnetic Beads were from Thermo Fisher Scientific (Waltham, NY, USA). Cholesterol was obtained from Sigma-Aldrich (St. Louis, MO, USA). The primary antibodies, rabbit monoclonal anti-AKT1 (ab81283), anti-AKT-1/2/3 (ab179463), anti-mTOR/p-mTOR (ab32028, ab109268), anti-HO-1 (ab52947), anti-Aconitase2 (Aco2)(ab129069), anti-lactate dehydrogenase(LDH)(ab134187), anti-pyruvate dehydrogenase E-1 $\beta$ (PDHE-1 $\beta$ ) (ab155996), antinuclear factor erythroid 2-like 2 (Nrf2) (ab62352) and anti-EBP (ab135745) were purchased from Abcam (Cambridge, MA, USA). Anti-histone H3.1 was obtained from Abmart. Antimalic dehydrogenase (MDH2) (\#8610) was obtained from Cell Signaling Technology. The anti-rabbit HRP-labeling and the antirabbit DyLight ${ }^{\mathrm{TM}}$ 488- and anti-mouse DyLight ${ }^{\mathrm{TM}}$ 633-labeled secondary antibodies were from KPL.

Cell culture. 293T and H9c2 cells (Cat. nos. GNHu17 and GNR5; obtained from Shanghai Cell Resource Center of Chinese Academy of Sciences, Shanghai, China) were cultured in $\mathrm{H}$-DMEM containing $10 \% \mathrm{FBS}$ at $37^{\circ} \mathrm{C}$ in a humidified $5 \% \mathrm{CO}_{2}$ atmosphere. According to a previous study (15), $5 \times 10^{5}$ H9c2 cells were plated into $100-\mathrm{mm}$ culture dishes, and cultured for $48 \mathrm{~h}$. For cell viability following cholesterol treatment, the cells were washed with phosphate-buffered saline (PBS) prior to removing the additional cholesterol.

Ethics statement. The experiments were approved by the institution's Ethics Committee for Investigation of Logistics University of the Chinese People's Armed Police Force, and all of the 20 animals were treated under humane care in compliance with the Public Health Service Policy on Humane Care and Use of Laboratory Animals.

Animals and treatments. Ten 24-week old male wild-type(WT) C57BL/6 mice were acquired from the Laboratory Animal Center of the Academy of Military Medical Sciences, and 10 24-week old male $\mathrm{HO}-1^{+/-}$mice were acquired from the South Model Animal Center of China. As a low HO-1 protein level is associated with high abortion rates (16), only 2 homozygote HO- $1^{-/}$mice survived out of 200 newborn HO-1-knockdown mice. Therefore, this study used HO- $1^{+/-}$mice to perform the subsequent experiment.

All mice were raised in a controlled environment at a temperature of $25^{\circ} \mathrm{C}$ and a $40-70 \%$ humidity with a 12-h light and dark cycle. Among the WT and $\mathrm{HO}-1^{+/-}$mice, 5 were fed with a normal diet while 5 were fed with a normal diet and added cholesterol (3.5 mg/kg) (17). Sixty days later, the weights of the mice were calculated, and the cardiac functions of the mice were assessed using cardiac ultrasound. Finally, the mice were sacrificed using cervical dislocation to collect samples for the Oil Red $\mathrm{O}$ staining and laser scanning confocal microscope image experiments.

Co-immunoprecipitation (Co-IP). Cells $\left(1 \times 10^{5}\right)$ were seeded into $100-\mathrm{mm}$ culture dish, and transfection was performed when cells reached $30-50 \%$. According to the transfection protocol, $10 \mu \mathrm{g}$ of pCDNA3.1-HO-1 and pCDNA3.1-blank vectors were respectively transferred into the $293 \mathrm{~T}$ cells using the TurboFect transfection reagent. After they were transfected for $24 \mathrm{~h}$, the cells were lysed with a buffer $(150 \mathrm{mmol} / \mathrm{l} \mathrm{NaCl}$, $1 \mathrm{mmol} / \mathrm{l} \mathrm{EDTA}, 50 \mathrm{mmol} / 1$ Tris- $\mathrm{HCl}, 5 \%$ glycerol, $0.1 \% \mathrm{NP}-40$ and cocktails) at $4^{\circ} \mathrm{C}$. The supernatants were collected by centrifugation at $4^{\circ} \mathrm{C}$. The concentration of protein was determined by the BCA assay. Co-IP was performed according to a previous study (18). Briefly, $10 \mu \mathrm{g}$ of rabbit anti-HO-1 antibody was added into $1 \mathrm{mg}$ supernatants of $293 \mathrm{~T} / \mathrm{HO}-1$ cells and then incubated overnight at $4^{\circ} \mathrm{C}$. This was followed by incubation with $25 \mu \mathrm{l}$ Pierce $^{\mathrm{TM}}$ Protein G Magnetic Beads for $2 \mathrm{~h}$ at $4^{\circ} \mathrm{C}$. After the cells were washed completely, the Co-IP product was obtained with a $50 \mu$ l elution buffer $[1.74 \mathrm{mmol} / 1$ sodium dodecyl sulfate (SDS), $0.037 \mathrm{mmol} / \mathrm{l}$ bromphenol blue, $50 \%$ glycerol, $0.25 \mathrm{~mol} / 1$ Tris- $\mathrm{HCl}$ and $2.5 \mathrm{mmol} / \mathrm{l} \mathrm{DTT}]$. Then the eluent was reduced with $10 \mathrm{mmol} / 1 \mathrm{DTT}$ for $10 \mathrm{~min}$ at $100^{\circ} \mathrm{C}$ and alkylated with $50 \mathrm{mmol} / \mathrm{l} \mathrm{IAA}$ at room temperature in the dark for $30 \mathrm{~min}$. Additionally, $10 \mu \mathrm{l}$ of the Co-IP products was used to perform western blot analysis using an anti-EBP antibody to validate the interaction between HO-1 and EBP.

Protein digestion and LC-MS/MS analysis. The Co-IP products were separated with $10 \%$ SDS-PAGE gel and then the gel was stained with Coomassie Blue G-250. The gel lane was then sliced into 8 bands followed by destaining and in-gel digestion with $10 \mathrm{ng} / \mu \mathrm{l}$ of trypsin (Promega, Madison, WI, USA) at $37^{\circ} \mathrm{C}$ overnight according to a previous study (19). The peptides of bands were extracted by the addition of $25 \mathrm{mmol} / \mathrm{l}$ ammonium bicarbonate and 5\% v/v FA (formic acid), and dried in a vacuum concentrator. The samples were later subjected to mass spectrometric analysis, and MS/MS analysis was performed as described previously (20). The raw data obtained were searched via the MaxqQuant (version 1.5.3.28 build) search engine against a decoy database/composite target to appraise the false discovery rate (FDR) (21). The target proteins were acquired from the Swiss-Prot Homo sapiens reference protein database (release 2015_08,69787 query number) and the decoy proteins were produced from pseudo-reversed sequences of the target proteins. Precursor ions were searched with an initial mass tolerance of $20 \mathrm{ppm}$. Only $b$ and $y$ ions were considered during the database search. Enzyme specificity was trypsin, with two missed cleavages allowed and peptides with at least 6 amino acids. The dynamic modifications for methionine oxidation $(+15.99492)$ and the static modification for cysteine carbamidomethylation (57.021465) were allowed. The FDR of peptides and proteins $<1 \%$ was accepted after appraisal based on the number of accepted decoy hits. 
Profiling of the global HO-1 interactome network. The Gene Ontology (GO) information for the HO-1 interaction proteins was submitted to DAVID for biological process (BP) and cellular component (CC) analysis (22), and the Homo sapiens species was selected as the background and species. The CluePedia plugin of the Cytoscape version 3.3 was used to generate the protein-protein interaction (PPI) network.

MTT assay. The MTT assay was carried out as referred to in a previous study (23). Briefly, a concentration of $1 \times 10^{4}$ cells was seeded into each well of a 96 -well plate (Corning, 3599). The cells were incubated with 10,100 and $500 \mathrm{mmol} / 1$ cholesterol for $12,24,36$ and $48 \mathrm{~h}$, and then were incubated with $5 \mathrm{mg}$ / $\mathrm{ml}$ MTT buffer for $5 \mathrm{~h}$. The optical density at $450 \mathrm{~nm}$ was measured using the SpectraMax Series microplate reader (Molecular Devices, Sunnyvale, CA, USA).

Quantification of adipose droplets by staining lipids with Oil Red $O$. H9c2 cells were seeded onto a 6-well plate at a density of $3 \times 10^{4} / \mathrm{ml}$ in H-DMEM medium. After the cells grew to $60-70 \%$ confluence, the cells were treated with $100 \mathrm{mmol} / \mathrm{l}$ cholesterol for 12, 24, 36 and $48 \mathrm{~h}$, according to a previous study (24), followed by incubation with staining buffer $(0.5 \%$ Oil Red $\mathrm{O}$ in pentanediol) for $15 \mathrm{~min}$, and then incubated at room temperature with hematoxylin for $2 \mathrm{~min}$. After washing the cells with pentanediol twice, the density of adipose droplets was measured by Image-Pro Plus 6.0 software (Media Cybernetics, Inc., Bethesda, MD, USA).

Nuclear protein extraction. H9c2 cells were treated with $100 \mathrm{mmol} / \mathrm{l}$ cholesterol for 12, 24, 36 and $48 \mathrm{~h}$, washed with PBS twice, and then the cells were suspended in lysis buffer A (10 mmol/l HEPES pH 7.9, $10 \mathrm{mmol} / 1 \mathrm{KCl}, 0.1 \mathrm{mmol} / \mathrm{l}$ EDTA, $0.1 \mathrm{mmol} / 1 \mathrm{EGTA}, 0.5 \% \mathrm{NP}-40,1 \mathrm{mmol} / 1 \mathrm{DTT}$ and protease inhibitor) and collected in tubes. The supernatants were collected after centrifugation. Buffer B [20 mmol/1 HEPES (pH 7.9), $0.4 \mathrm{~mol} / 1 \mathrm{NaCl}, 1 \mathrm{mmol} / 1$ EDTA, $1 \mathrm{mmol} / 1$ EGTA, $1 \mathrm{mmol} / \mathrm{L} \mathrm{DTT}$ and protease inhibitor] was added into the nuclear pellet, and incubated on ice for $30 \mathrm{~min}$. After centrifugation for $15 \mathrm{~min}$, the supernatant was collected.

Western blot analysis. H9c2 cells were treated with $100 \mathrm{mmol} / \mathrm{l}$ cholesterol for 12, 24, 36 and $48 \mathrm{~h}$, and cells were lysed with RIPA buffer at $4^{\circ} \mathrm{C}$. The concentration of protein was measured using the BCA assay. Then $60 \mu \mathrm{g}$ of the samples of the different groups was separated by $10 \%$ SDS-PAGE and then were transferred onto a $0.22-\mu \mathrm{m}$ nitrocellulose membrane by a semi-dry electroblotter. The membranes were respectively incubated with the primary antibodies $(1: 1,000)$ overnight at $4^{\circ} \mathrm{C}$ followed by incubation with the secondary antibody $(1: 5,000)$ for $1 \mathrm{~h}$ at room temperature. The concentration of protein was detected using the ECL immunoblotting reagent. The gray values of the bands were quantified with the Scion Image software and were normalized with $\beta$-actin and histone.

Measurements of the cardiac function of the mice using cardiac ultrasound. The mice were divided into groups as previously described. After they were fed for 60 days, the weights of the mice were measured. Then the cardiac function was measured using the Vevo 2100 Imaging System. A
MS-400 scan head (30 MHz) was used to acquire the left ventricular short axis (SAX) and left ventricular long axis (PSLAX) views of the mouse ventricle in M-mode. The left ventricular short axis shortening (LVFS\%), left ventricular ejection fraction (LVEF\%) and left ventricular (LV) mass were analyzed by Visual Sonic Vevo 2100 software, and LV masses were normalized with the corresponding weight of the mice.

Quantification of adipose droplets by staining tissue slices with Oil Red $O$. Myocardial tissues of the four previously described groups were fixed in $4 \%$ paraformaldehyde for $24 \mathrm{~h}$ and dehydrated in $30 \%$ sucrose for $3 \mathrm{~h}$. After they were embedded in tissue freezing medium (Leica, 14020108926), they were processed into $7-\mu \mathrm{m}$ frozen sections using a freezing microtome (Leica, CM1860). Oil Red O staining was performed as previous described (25). Briefly, five slices of each group were first soaked in $60 \%$ isopropanol for $10 \mathrm{~min}$ followed by incubation with staining buffer $(60 \%$ Oil Red $\mathrm{O}$ in water) for $25 \mathrm{~min}$, and the slices were later differentiated in $75 \%$ ethanol containing $1 \%$ hydrochloric acid for $2 \mathrm{~min}$. The slices were incubated with hematoxylin buffer at room temperature for $2 \mathrm{~min}$. After washing them with pentanediol twice, the lipid accumulation in myocardial tissues was observed using the Image-Pro Plus 6.0 software (Media Cybernetics, Inc.).

Laser scanning confocal microscope image. A total of $1 \times 10^{4}$ cells were seeded onto a confocal plate (Nest, 801002) and treated with cholesterol as previously described. The ICC was performed as in a previous study (26). Briefly, the cells and 5 frozen slices from four groups were fixed in precooling methanol for $10 \mathrm{~min}$ and then permeabilized with $0.5 \%$ Triton $\mathrm{X}-100$ for $20 \mathrm{~min}$ at $37^{\circ} \mathrm{C}$. Then they were incubated with the anti-HO-1 and anti-EBP primary antibody (1:100) at $4^{\circ} \mathrm{C}$ for $12 \mathrm{~h}$ followed by incubation with the DyLight ${ }^{\mathrm{TM}} 488$ and DyLight ${ }^{\mathrm{TM}}$ 633-labeled secondary antibody for $1 \mathrm{~h}$ at $37^{\circ} \mathrm{C}$, as well as dyed in $1 \mu \mathrm{g} / \mathrm{ml}$ DAPI for $5 \mathrm{~min}$. Cells and the slices were visualized using confocal microscopy (objective, 20X; Leica TCS SP8). The images were analyzed using IPP 6.0 software.

Statistical analysis. Data are expressed as the means \pm SEM of three independent experiments. The differences between groups of the in vivo experiments were analyzed using one-way ANOVA. Differences between groups of the in vitro experiments were analyzed using multi-way ANOVA. A P-value $<0.05$ was used to determine a statistically significant difference.

\section{Results}

Interaction between $\mathrm{HO}-1$ and EBP. A total of $137 \mathrm{HO}-1$ interactive proteins were identified using overlap of two repeated filtering with control groups, and several of the interactive proteins are listed in Fig. 1A. In particular, a sterol isomerase named EBP, an integral membrane protein of the endoplasmic reticulum, catalyzes the conversion of Delta (8)-sterols to their corresponding Delta (7)-isomers for involvement in the cholesterol metabolism. The western blot analysis result of the Co-IP products confirmed that HO-1 and EBP indeed were interactive (Fig. 1B). Based on the results of the interac- 
A HO--1 purification

\begin{tabular}{ccc}
\hline Gene names & Pepides & Coverage (\%) \\
\hline RPLP2 & 9 & 92.2 \\
CSTA & 7 & 86.7 \\
K2C1 & 50 & 68.8 \\
RS4X & 21 & 68.1 \\
K1C14 & 36 & 67.4 \\
RAB7A & 9 & 49.3 \\
HMOX1 & 13 & 41 \\
HSP71 & 21 & 33.5 \\
CASPE & 7 & 27.7 \\
EBP & 2 & 9.6 \\
\hline
\end{tabular}

B

MW

(kDa)

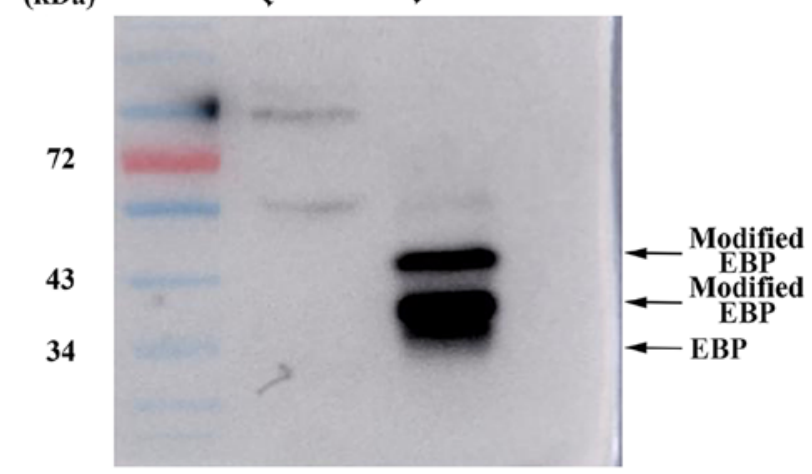

C
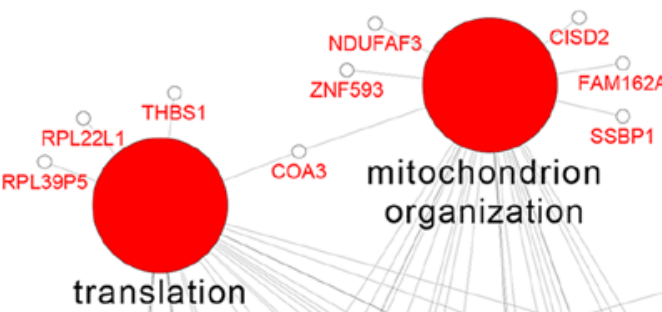

COA3 mitochondrion organization

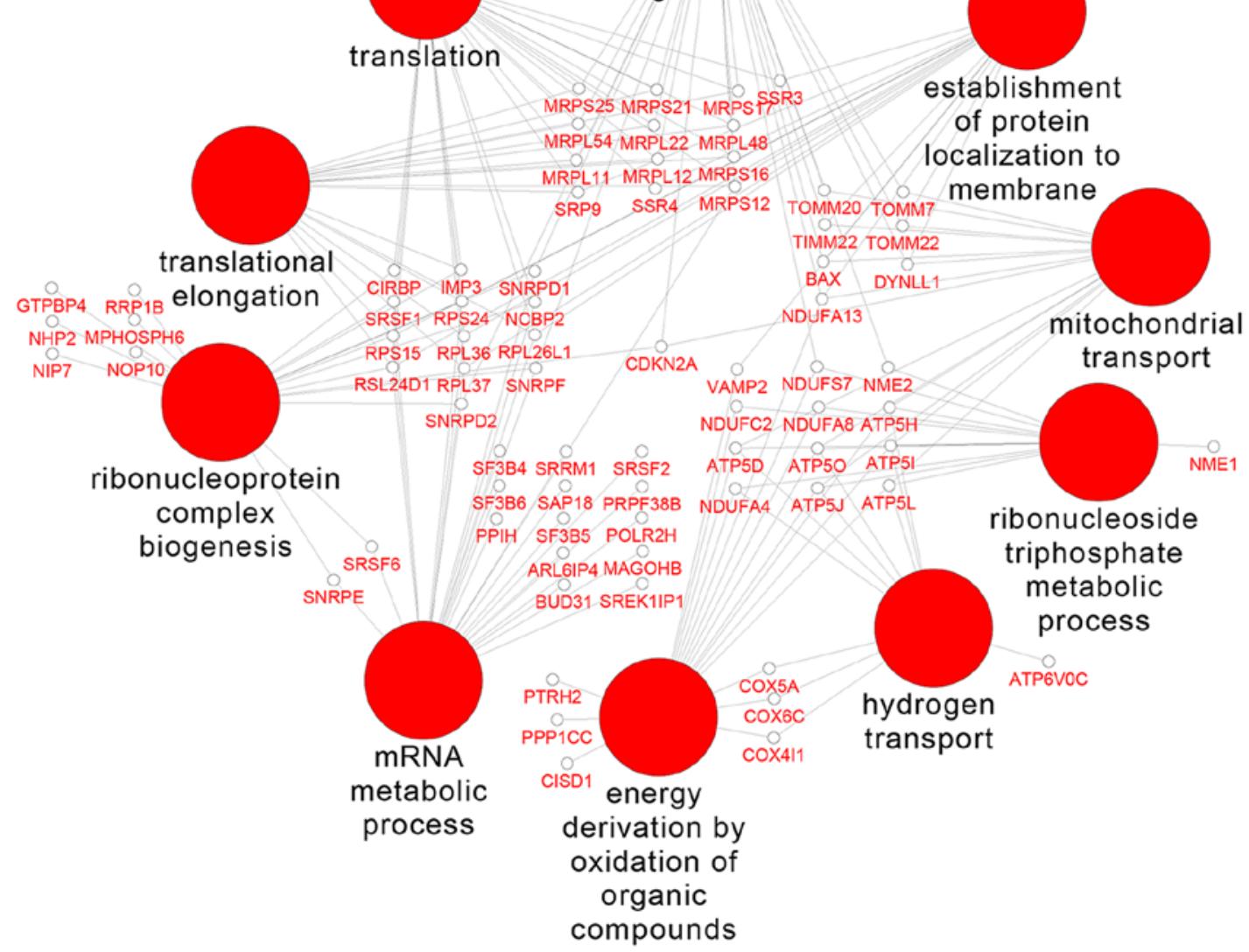

Figure 1. Global profiling and mapping of the heme oxygenase-1 (HO-1)-interacting protein network. (A) The major interactive proteins from two repeats of the MS analysis are shown in the table. (B) The western blot analysis results indicated that HO-1 and emopamil-binding protein (EBP) are interactive. (C) The network of HO-1 interacting proteins using Cytoscape 3.3 software.

tome, we speculated that overexpression of HO-1 may cause a cardioprotective adaptation for improvement under a high concentration cholesterol environment.

Global profiling and mapping of the HO-1-interacting protein network. By GO enrichment analysis, the HO-1-interacting proteins were found to be mainly involved in BPs (Fig. 1C), including oxidative phosphorylation, ATP synthesis-coupled proton transport, mitochondrion organization and nitrogen catabolic process. Meanwhile, these proteins were also found to participate in $\mathrm{CCs}$, such as mitochondrion, endoplasmic reticulum and transport vesicles.

Effects of cholesterol on the growth of H9c2 cells. The MTT assay was performed to determine the viability rates of the H9c2 cells treated with 10,100 and $500 \mathrm{mmol} / 1$ cholesterol for $12,24,36$ and $48 \mathrm{~h}$. The viability rates were $83.92 \pm 0.51$, $87.99 \pm 1.22,90.00 \pm 0.96$ and $91.35 \pm 2.22 \%$ in the $10 \mathrm{mmol} / \mathrm{l}$ 


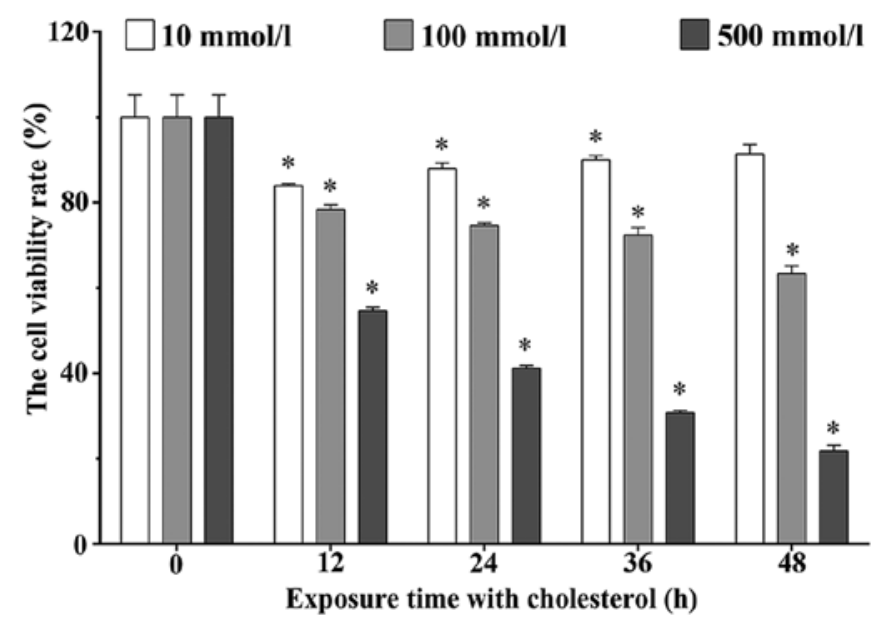

Figure 2. Effects of cholesterol on the proliferation ability of H9c2 cells Cholesterol inhibited the proliferation of $\mathrm{H} 9 \mathrm{c} 2$ cells in a time- and dosedependent manner. Data are presented as means \pm SEM of three individual experiments. $\mathrm{P}$ values were calculated using one-way ANOVA. ${ }^{*} \mathrm{P}<0.05$ vs. the control group.

cholesterol treatment group. These rates were $78.33 \pm 1.14$, $74.62 \pm 0.54,72.36 \pm 1.78$ and $63.26 \pm 1.86 \%$ in the $100 \mathrm{mmol} / 1$ cholesterol treatment groups, and these rates were 54.60 \pm 0.89 , $41.12 \pm 0.74,30.69 \pm 0.59$ and $21.76 \pm 1.39 \%$ in the $500 \mathrm{mmol} / 1$ cholesterol treatment groups, respectively. As shown in Fig. 2, cholesterol significantly inhibited the $\mathrm{H} 9 \mathrm{c} 2$ cell viability in a dose- and time-dependent manner $(\mathrm{P}<0.05)$.

Upregulated expression of $\mathrm{HO}-1$ and EBP plays a protective role during cholesterol stimulation. We speculated that a high concentration of cholesterol could result in the overexpression of HO-1 by activation of the Nrf2, AKT and mTOR signaling pathways. The western blot results showed that the HO-1 expression levels in the $\mathrm{H} 9 \mathrm{c} 2$ cells treated with cholesterol for 24, 36 and 48 h were 1.72-, 1.87- and 2.00-fold, respectively, compared with those of the control group $(\mathrm{P}<0.05)$ (Fig. $3 \mathrm{~A}$ and $\mathrm{B})$. We also found that the abundance of post-translational modified and degraded HO-1 was gradually increased in the cholesterol treatment groups. The western blot results showed that the EBP expression levels in the H9c2 cells treated with cholesterol for 12, 24, 36 and $48 \mathrm{~h}$ were 1.66-, 2.34-, 2.44and 2.26-fold, respectively, compared with that of the control group $(\mathrm{P}<0.05)$ (Fig. 3A and $\mathrm{C}$ ).

We also found that expression of several critical molecules in lipid metabolism, Nrf2, AKT and mTOR, was significantly altered. Nrf2 is a type of transcription activator that binds to antioxidant response (ARE) elements in the promoter regions of downstream target genes. Nrf2 expression in H9c2 cells treated with cholesterol was significantly increased compared to that noted in the control group $(\mathrm{P}<0.05)$ (Fig. 4A and $\mathrm{B})$. We also determined the expression level of Nrf2 in the cytoplasm and nucleus. The expression level of Nrf2 in the cytoplasm was significantly decreased after treatment with cholesterol for $48 \mathrm{~h}(\mathrm{P}<0.05)$ (Fig. 5A and $\mathrm{C}$ ) and the expression level of Nrf2 in the nucleus was significantly increased after treatment with cholesterol $(\mathrm{P}<0.05)$ (Fig. 5B and D). AKT and mTOR belong to the serine/threonine protein kinases, and are central regulators of cellular metabolism and growth in response to energy supplements and stress signals. We also found that the mTOR expression levels in the 12, 24 and $36 \mathrm{~h}$ cholesterol treatment groups were significantly increased compared with that of the control group. However, the expression level in the 48-h cholesterol treatment group was significantly decreased $(\mathrm{P}<0.05)$. Notably, $\mathrm{p}$-mTOR in the 12 -h cholesterol treatment group was increased $(\mathrm{P}<0.05)$. Meanwhile, we also observed that the mTOR phosphorylation process was not obviously changed at 24 and $36 \mathrm{~h}$. However, p-mTOR was significantly decreased in the H9c2 cells treated with cholesterol for $48 \mathrm{~h}$ compared with that of the control group $(\mathrm{P}<0.05)$ (Fig. 4C). This study confirmed that AKT expression in the H9c2 cells treated with cholesterol for 12 and $24 \mathrm{~h}$ was significantly increased compared to that of the control group $(\mathrm{P}<0.05)$, and the p-AKT level in all cholesterol treatment groups was significantly increased compared to that of the control group $(\mathrm{P}<0.05)$. The ratio of $\mathrm{p}-\mathrm{AKT} / \mathrm{AKT}$ in the cholesterol treatment groups was significantly increased compared to that of the control group $(\mathrm{P}<0.05)$ (Fig. 4D). These results suggest that cholesterol stimulation induces an upregulated expression of HO-1 and EBP by activation of the Nrf2, AKT and mTOR signaling pathways.

Interaction between $\mathrm{HO}-1$ and EBP alleviates the lipid accumulation in $H 9 c 2$ cells as determined using laser scanning
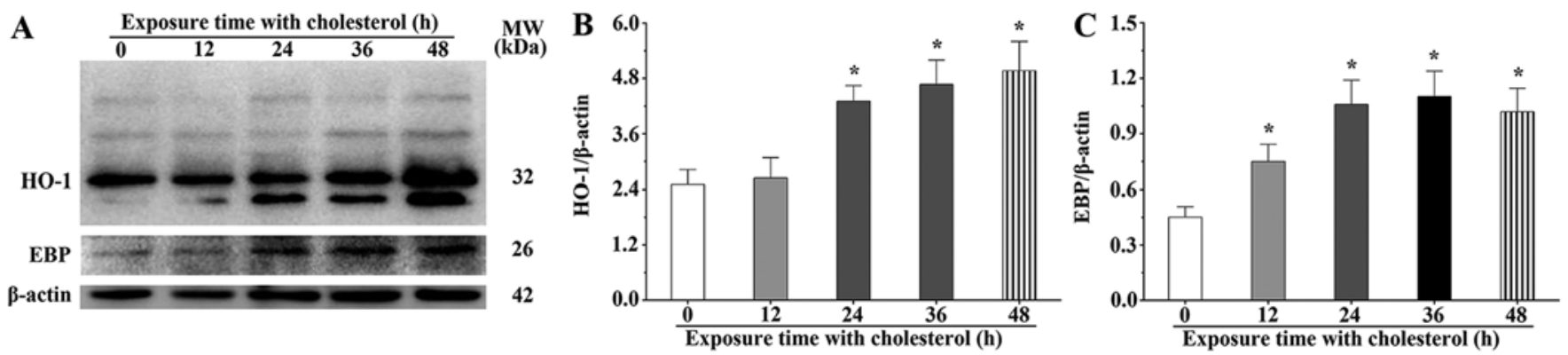

Figure 3. Effects of cholesterol on the expression of heme oxygenase-1 (HO-1) and emopamil-binding protein (EBP) in H9c2 cells following cholesterol stimulation. (A) Western blot analysis was used to evaluate the expression levels of HO-1 and EBP. (B and C) The expression levels of HO-1 and EBP quantified by densitometry. $\beta$-actin was used as an internal control. Data are presented as means \pm SEM of three individual experiments. P-values were calculated using one-way ANOVA. ${ }^{*} \mathrm{P}<0.05$ vs. the control group. 

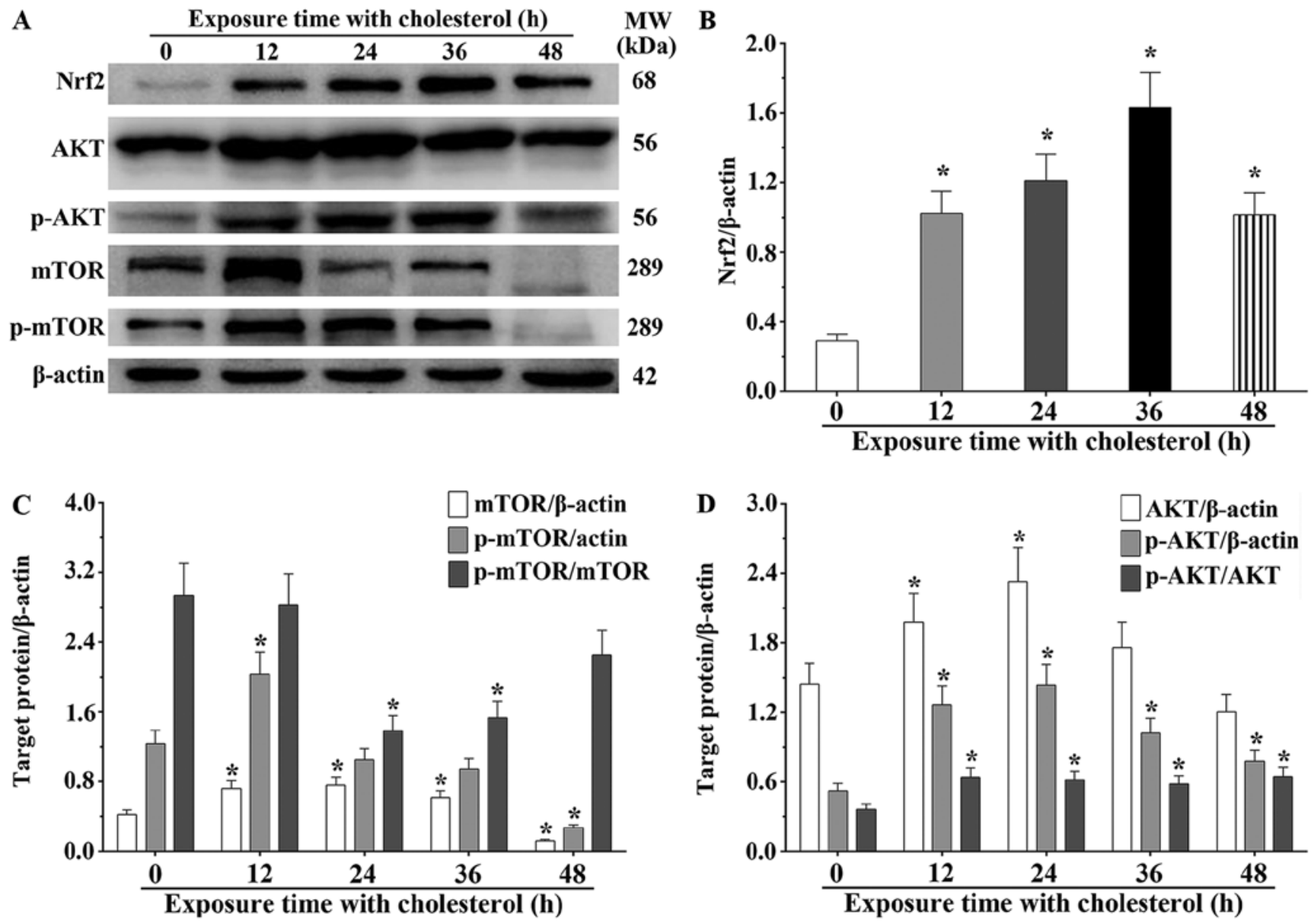

Figure 4. Effects of cholesterol on the expression of heme oxygenase-1 (HO-1)-related molecules. (A) Western blot analysis was used to evaluate the expression levels of nuclear factor erythroid 2-like 2 (Nrf2), AKT, p-AKT, mTOR and p-mTOR proteins (B-D) The expression levels of Nrf2, AKT, p-AKT, mTOR and p-mTOR proteins as quantified by densitometry. $\beta$-actin was used as an internal control. Data are presented as means \pm SEM of three individual experiments. $\mathrm{P}$-values were calculated using one-way ANOVA. ${ }^{*} \mathrm{P}<0.05$ vs. the control group.
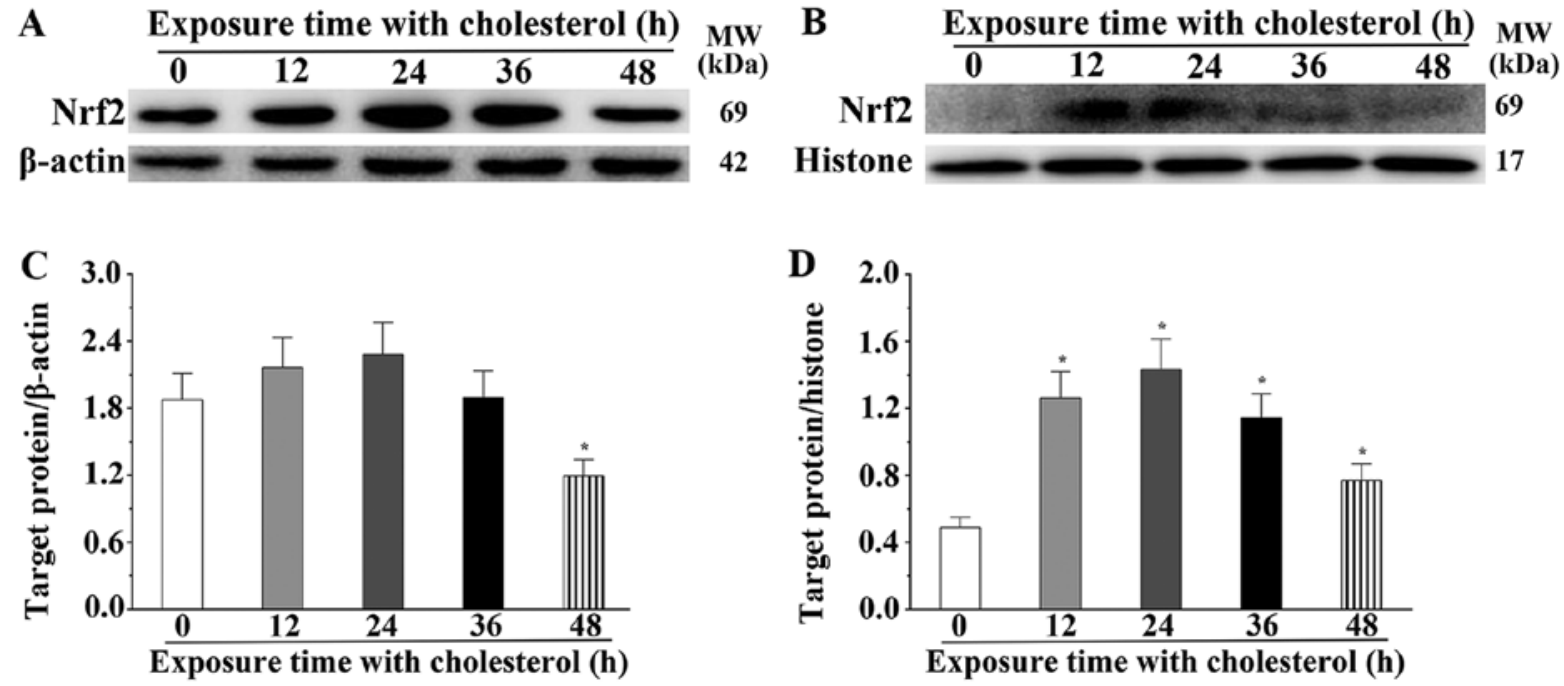

Figure 5. Effects of cholesterol on the expression of nuclear factor erythroid 2-like 2 (Nrf2). (A) Western blot analysis was used to evaluate the expression levels of Nrf2 in the cytoplasm. (B) Western blot analysis was used to evaluate the expression levels of Nrf2 in the nucleus. (C and D) The expression levels of Nrf2 in the cytoplasm and nucleus as quantified by densitometry. $\beta$-actin was used as an internal control. Data are presented as means \pm SEM of three individual experiments. $\mathrm{P}$ values were calculated using one-way ANOVA. ${ }^{*} \mathrm{P}<0.05$ vs. the control group.

confocal microscope image. Using Oil Red O staining, we found that the amount of lipid droplets in the H9c2 cells treated with cholesterol was significantly increased compared to that of the control group (Fig. 6A). The results of the confocal 
A

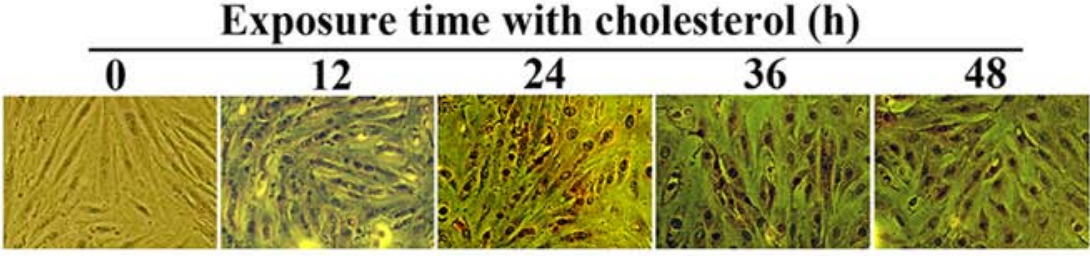

B

Time (h) DAPI

HO-1

EBP

Merge

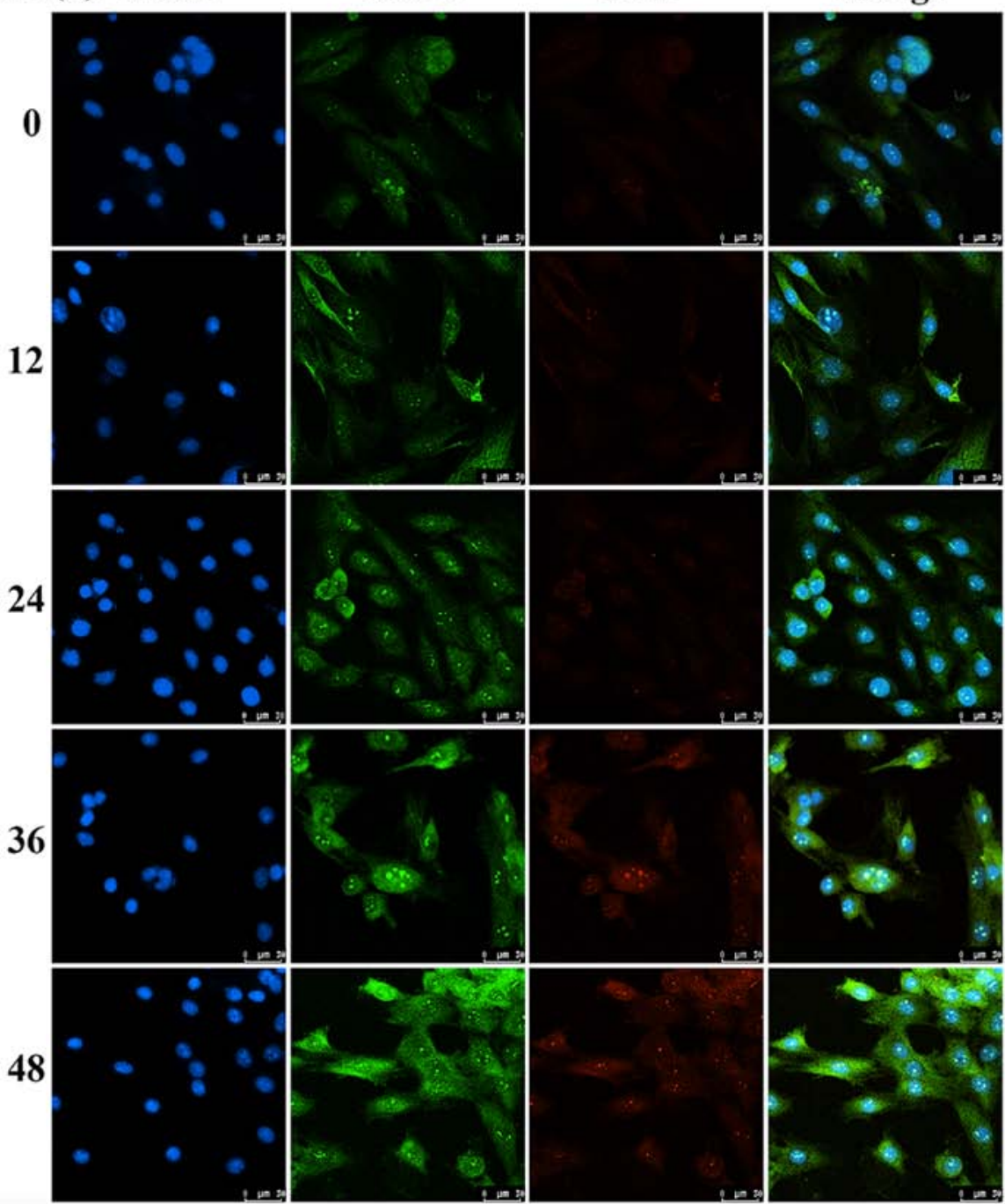

Figure 6. Measurements of lipid accumulation and location of heme oxygenase-1 (HO-1) and emopamil-binding protein (EBP) in H9c2 cells following cholesterol stimulation. (A) Oil Red O staining indicated that the concentration of cholesterol was increased in the cholesterol groups. (B) The interaction between HO-1 and EBP was noted in the cell membrane, cytoplasm and nucleus, and both showed the same upregulated expression trend using confocal microscopy (magnification, $\mathrm{x} 200$ ).

microscopy showed that the expression levels of HO-1 and EBP were significantly upregulated under cholesterol stimulation. We also confirmed that HO-1 and EBP have the same location in $\mathrm{H} 9 \mathrm{c} 2$ cells according to the confocal image (Fig. 6B). These results also confirmed the interaction between $\mathrm{HO}-1$ and $\mathrm{EBP}$ to alleviate lipid accumulation.

HO-1 overexpression alleviates $H 9 c 2$ cell hypoxia by inhibition of the glucose metabolism process. Hypoxia inducible factor-1 (HIF-1) is a critical regulatory factor for stress reactions, which usually degrades in the normal oxygen status; however, it maintains its stable state under a hypoxic status.
After cholesterol stimulation for 12, 24 and $36 \mathrm{~h}$, we noted that expression levels of HIF-1 $\alpha$ were significantly increased compared with the control group $(\mathrm{P}<0.05)$ (Fig. 7A and $\mathrm{B}$ ). However, the expression level of HIF-1 $\alpha$ reverted to the normal status after cholesterol stimulation for $48 \mathrm{~h}$. LDH, involved in the final step of aerobic glycolysis, catalyzes the conversion of L-lactate and NAD to pyruvate and NADH. After cholesterol stimulation for 36 and $48 \mathrm{~h}$, LDH expression levels were significantly downregulated $(\mathrm{P}<0.05)$. However, LDH expression levels in the 12 and $24 \mathrm{~h}$ cholesterol treatment groups were not obviously different compared with that of the control group $(\mathrm{P}<0.05)$ (Fig. 7C). Aco2, a critical enzyme in 
A

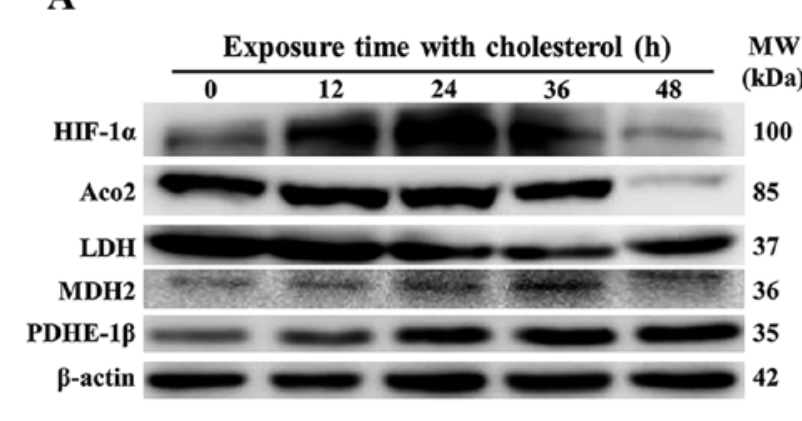

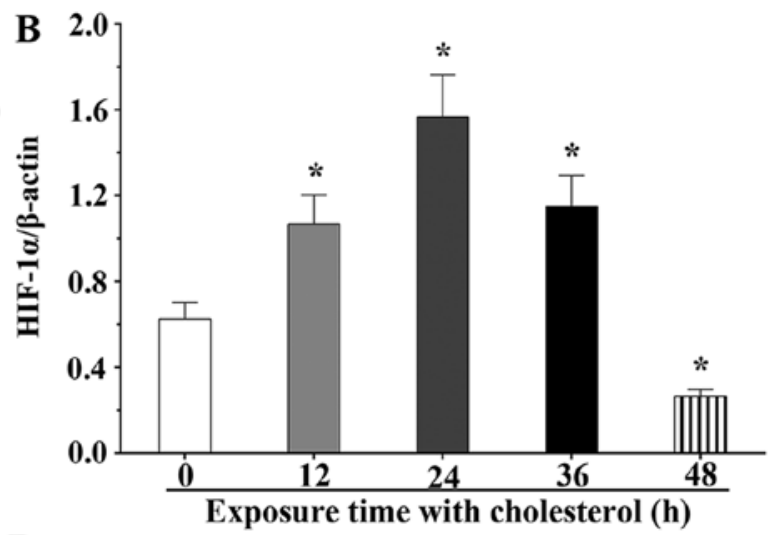
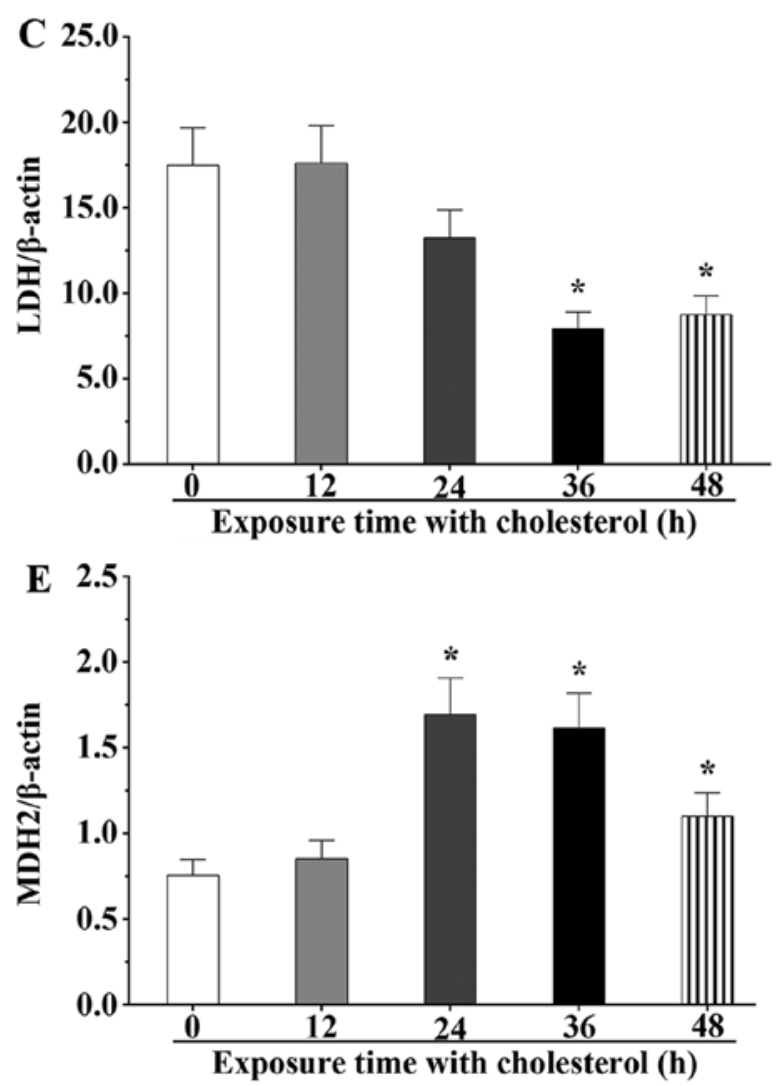
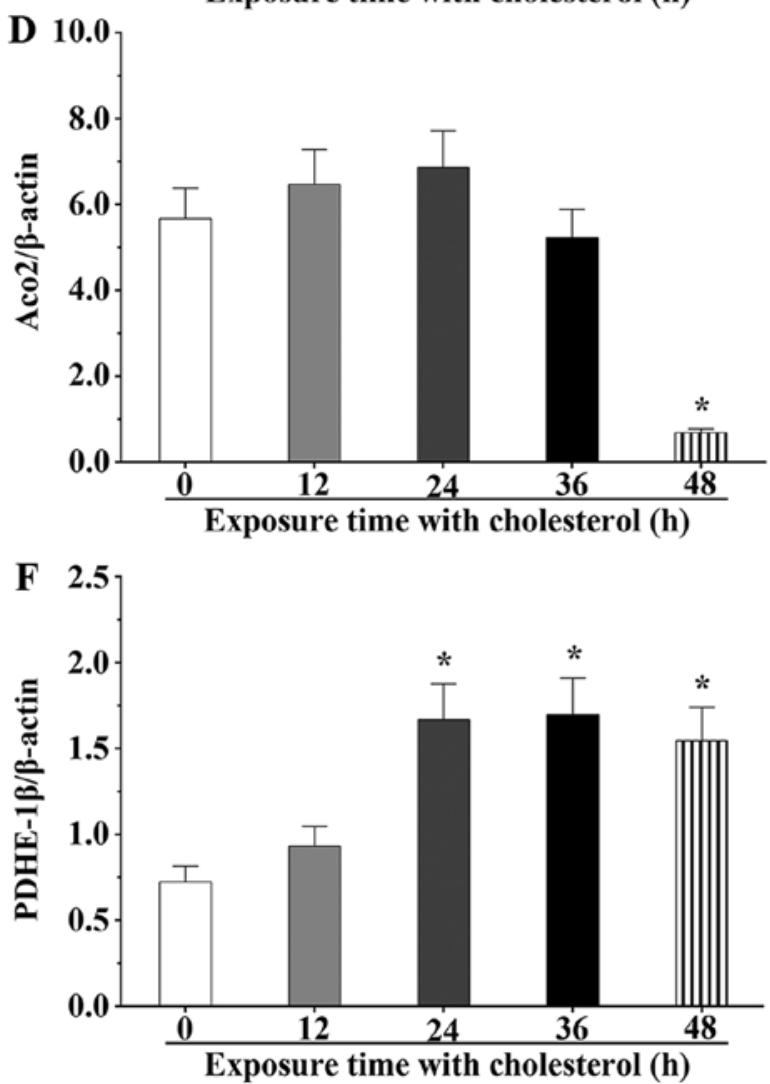

Figure 7. Cholesterol inhibits the expression of LDH and activates the expression of hypoxia inducible factor-1 $\alpha$ (HIF-1 $\alpha$ ) and mitochondrial enzymes. (A) Western blot analysis was used to evaluate the expression levels of each protein. $\beta$-actin was used as an internal control. (B-F) The expression level of each protein was quantified by densitometry. Data are presented as means \pm SEM of three individual experiments. P-values were calculated using one-way ANOVA. ${ }^{*} \mathrm{P}<0.05$ vs. the control group.

the Krebs cycle, catalyzes citric acid into aconitic acid. After cholesterol stimulation for $48 \mathrm{~h}$, Aco 2 expression levels were significantly downregulated $(\mathrm{P}<0.05)($ Fig. 7D). MDH2, a crucial enzyme of malic acid shuttle, transferred malic acid into the mitochondria matrix. The results showed that the expression level of $\mathrm{MDH} 2$ was significantly upregulated after cholesterol stimulation for 24, 36 and $48 \mathrm{~h}(\mathrm{P}<0.05)$ (Fig. 7E). PDHE-1 $\beta$ catalyzes pyruvate acid in the mitochondria matrix into acetyl-CoA. Our experiment showed that the expression level of PDHE-1 $\beta$ was significantly increased at 24, 36 and $48 \mathrm{~h}(\mathrm{P}<0.05)$ (Fig. 7F). These findings indicate that overexpression of HO-1 reduced the oxygen consumption to alleviate the hypoxic effect by inhibition of glycolysis and aerobic oxidation processes after cholesterol treatment. Hence, we confirmed that HO-1 displayed cardioprotective effects against the oxidative damage induced by cholesterol in cardiomyocytes.

HO-1 plays a protective role during cholesterol stimulation in an in vivo experiment. We found that the mouse weight in all groups was not significantly different between the normal diet and high-fat diet groups ( $\mathrm{P}>0.05)$. Using cardiac ultrasound, we determined that the values for LVEF\% in the WT mice with a normal diet, the WT mice with a high fat diet, the $\mathrm{HO}-1^{+/}$mice with a normal diet and the $\mathrm{HO}-\mathrm{1}^{+/}$mice with a high-fat diet were $1.51 \pm 0.11,1.34 \pm 0.20,1.66 \pm 0.08$ and $1.21 \pm 0.09$, respectively. The values of LVFS\% in these four groups were $0.75 \pm 0.06$, $0.64 \pm 0.11,0.84 \pm 0.05$ and $0.57 \pm 0.05$, and the LV mass in these four groups were $2.49 \pm 0.30,2.89 \pm 0.37,3.52 \pm 0.29$ and $3.03 \pm 0.32$, respectively, according to the data obtained from 

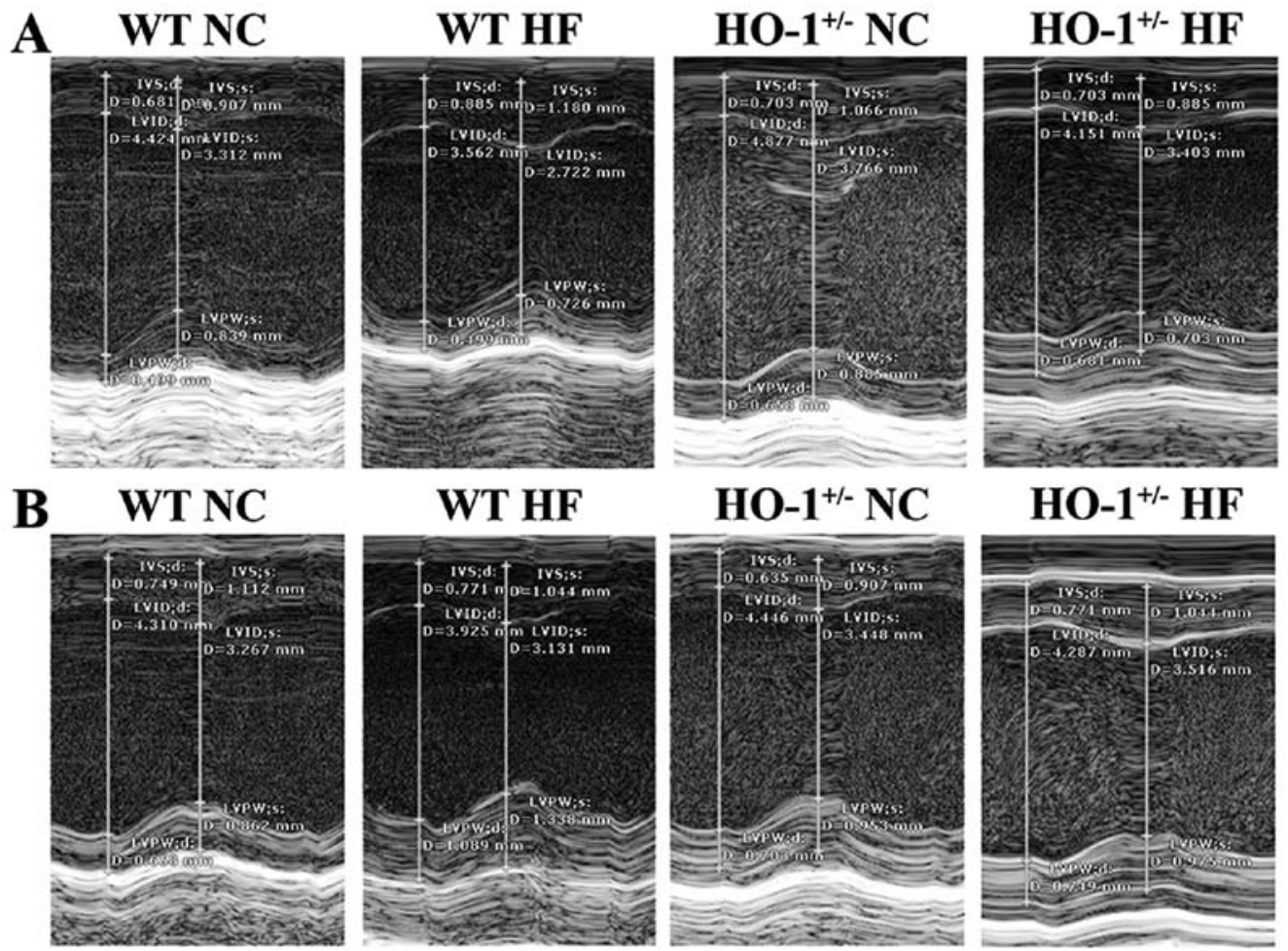

Figure 8. Measurements of left ventricular short axis shortening (LVFS\%), left ventricular ejection fraction (LVEF\%) and left ventricular (LV) mass in the wild-type (WT) and heme oxygenase-1 (HO-1) $)^{+/-}$mice in 5 individual experiments using cardiac ultrasound. (A) Images of the left ventricle from SAX views illustrating the measurements obtained. (B) Images of the left ventricle from PSLAX views illustrating the measurements obtained. The diameters of mice fed a high-fat diet were decreased compared to the normal diet groups from the images.

the SAX view (Fig. 8A). The values of LVEF\% of mice in these four groups were $1.46 \pm 0.07,1.27 \pm 0.19,1.69 \pm 0.08$ and $1.19 \pm 0.08$, respectively. The values of LVFS\% of these four groups were $0.73 \pm 0.04,0.61 \pm 0.10,0.86 \pm 0.05$ and $0.56 \pm 0.04$, and the LV mass of these four groups were $3.01 \pm 0.18$, $3.34 \pm 0.41,3.62 \pm 0.30$ and $3.56 \pm 0.28$, respectively, according to the data obtained from the PSLAX view (Fig. 8B). In addition, all values were normalized with the corresponding weight of the mice. The LVEF\% and the LVFS\% of the $\mathrm{HO}-1^{+-}$mice fed the high-fat diet was significantly decreased compared to the WT mice fed a normal diet $(\mathrm{P}<0.05)$. The LV mass of the HO- $1^{+/-}$mice fed a normal diet was significantly higher than the WT mice fed a normal diet $(\mathrm{P}<0.05)$ according to the data obtained from the SAX view. The LVEF\% and the LVFS\% of the $\mathrm{HO}-\mathrm{1}^{+/-}$mice fed a normal diet were significantly decreased compared to those of the WT mice fed a normal diet $(\mathrm{P}<0.05)$, and the LVEF\% and LVFS\% of the $\mathrm{HO}-1^{+/-}$mice fed a high fat diet were significantly decreased compared to those of the $\mathrm{HO}-1^{+-}$mice fed a normal diet $(\mathrm{P}<0.05)$. The LV mass of the $\mathrm{HO}-1^{+/}$mice fed a normal diet was significantly higher than the WT mice fed a normal diet $(\mathrm{P}<0.05)$ according to the data obtained from the PSLAX view.

Interaction between $\mathrm{HO}-1$ and EBP alleviates lipid accumulation in the in vivo experiment. Using Oil Red O staining, we found that the amount of lipid droplets in the myocardium of mice treated with cholesterol was also significantly increased compared with that in the mice fed a normal diet. The amount of lipid droplets in the HO-1 $1^{+/}$mice was significantly increased compared with that noted in the WT mice (Fig. 9A). We also confirmed that HO-1 and EBP are co-located in the myocardium according to the confocal image (Fig. 9B).

\section{Discussion}

HO-1, an essential enzyme in heme catabolism, is activated at high concentrations of heme and during a certain pathophysiological status, including oxidative stress, high glucose and viral infection, and exhibits cytoprotective effects $(27,28)$. However, the detailed mechanism remains obscure. Our experiment showed that the signaling network of $137 \mathrm{HO}-1$ interactive proteins was mainly distributed in oxidative phosphorylation, mitochondrion organization processes and endoplasmic reticulum and transport vesicle cellular components (29). Interestingly, we found that EBP is a HO-1 interactive proteins and is a sterol isomerase, closely related to lipid metabolisms, endoplasmic reticulum and vesicular fraction. The HO-1/EBP interaction was also confirmed both in vivo and in vitro using confocal microscopy. Moreover, we found that HO-1/EBP interaction not only occurred in the cytoplasm, but also in the nucleus and membrane. Meanwhile, our results also showed that HO-1 and EBP expression had a trend of consistency, presenting upregulated expression under cholesterol stimulation. Hence, we suggested that HO-1 interacts with EBP and are involved in lipid metabolism, consume redundant cholesterol, and alleviate oxidative stress effects caused by cholesterol.

HO-1 usually is induced by a variety of signal transduction pathways that activate different transcription factors, including Bach2, p53, CREB and Nrf2 (30). Nrf2 recognizes specific 


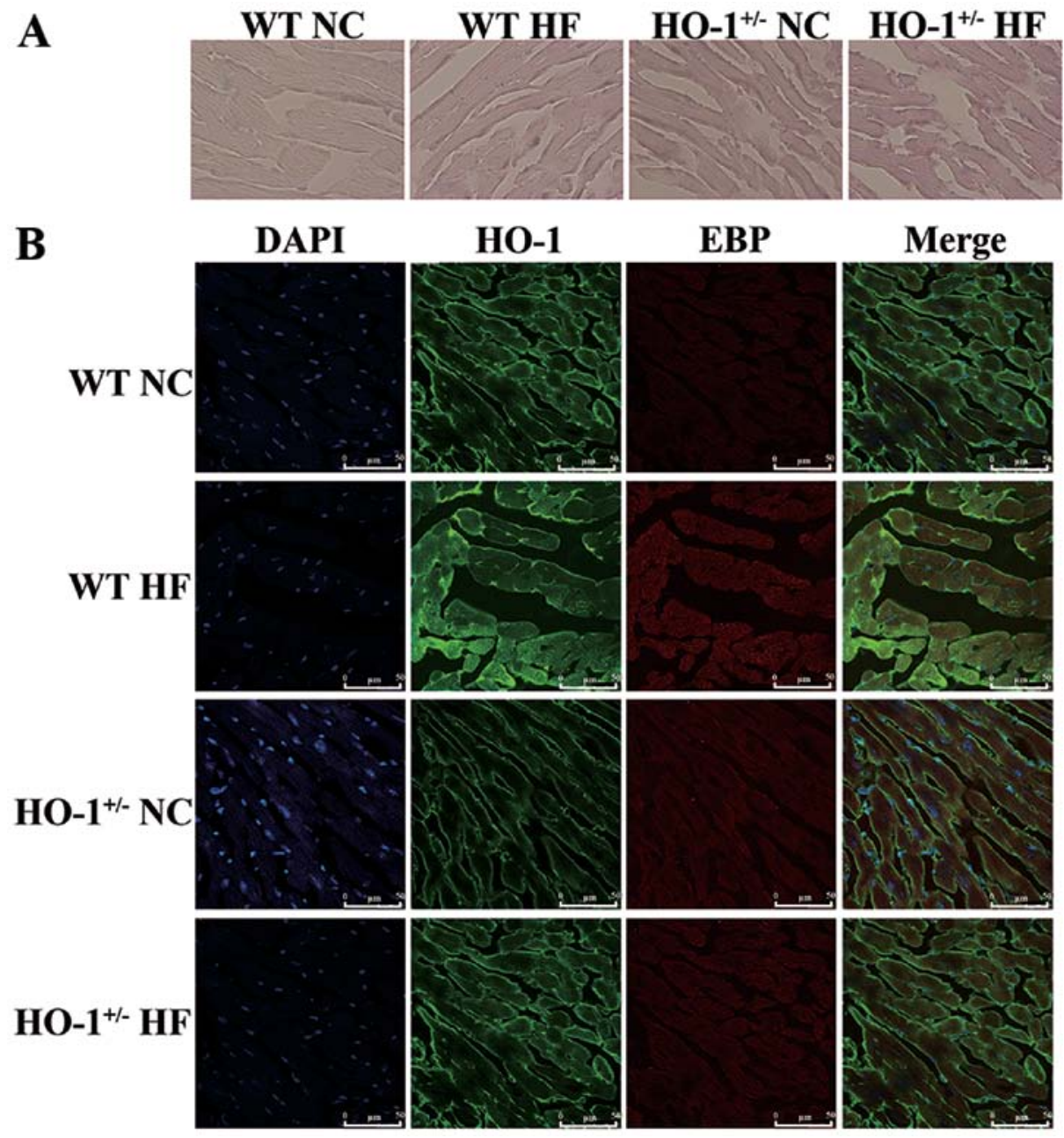

Figure 9. Measurements of lipid and the location of heme oxygenase-1 (HO-1) and emopamil-binding protein (EBP) in myocardial tissues. (A) Oil Red O staining indicated that the concentration of lipids was increased in the high-fat diet groups and was more significant in the HO- $1^{+/}$groups. (B) HO-1 and EBP had the same location and the expression levels were downregulated in the $\mathrm{HO}-1^{+/}$group and was upregulated after cholesterol stimulation (magnification, $\mathrm{x} 200)$.

DNA-binding elements of the HO-1 promoter (31-33). This study showed that cholesterol stimulation induced the upregulation of Nrf2 expression in cardiomyocytes, and then caused the upregulation of HO-1 expression. Cholesterol simulation not only markedly evaluated the AKT expression, but also increased Nrf2 expression $(34,35)$. Our results suggested that cholesterol may increase the intercellular reactive oxygen species (ROS) level and activate the PI3K/AKT signaling pathway, and then increase the Nrf2 expression and promote its separation from the Keap1-Nrf2 complex, which translocates to the nucleus and binds the promoter of HO-1 and plays an antioxidant role in cardiomyocytes. Our results also indicate that cholesterol simulation significantly increased the expression levels of AKT and p-AKT in cardiomyocytes by activation of the PI3K/AKT signaling pathway, which could not only evaluate the AKT expression, but it also increased the intercellular $\mathrm{Ca}^{2+}\left(\left[\mathrm{Ca}^{2+}\right]_{\mathrm{i}}\right)$ concentration. $\left[\mathrm{Ca}^{2+}\right]_{i}$ plays a critical role in translocation of $\mathrm{Nrf} 2$ to the nucleus to perform the transcriptional factor function (36-38). Meanwhile, we also noted that cholesterol increased the expression levels of mTOR and p-mTOR in cardiomyocytes. mTOR, a type of serine/threonine protein kinase, mediates cellular responses to stresses such as DNA damage and nutrient deprivation. It acts as a part of two structurally and functionally distinct signaling complexes, mTORC1 and mTORC2. Research has confirmed that mTOR inhibitor molecules (TSC1/TSC2) inhibit mTOR activity. Activation of PI3K and AKT, involved in the phosphorylation of TSC1/TSC2 promoted mTOR activity (39). In this study, the expression levels of Nrf2, AKT, p-AKT, mTOR and p-mTOR following cholesterol stimulation for $48 \mathrm{~h}$ were significantly decreased compared to those following cholesterol stimulation for 24 and $36 \mathrm{~h}$. However, the expression levels of HO-1 and EBP were not different in any of the cholesterol stimulation groups.

Hyperlipidemia usually alters the balance of cellular oxygen levels and induces hypoxia (40). HIF-1 is a critical regulatory factor for stress reaction and belongs to downstream molecules of the mTOR signaling pathway. It is activated by oxygen-mediated protein post-translational modification and cytoplasm/nucleus translocation under hypoxic condition. HIF-1 $\alpha$ is usually degraded in a normal oxygen condition; however, it maintains its stable state under hypoxia (41). The present study showed that the expression level of HIF-1 $\alpha$ following cholesterol stimulation for 12, 24 and $36 \mathrm{~h}$ was significantly increased compared to the control group. 
However, in the $48 \mathrm{~h}$ group, there was no difference. The result confirmed that $\mathrm{H} 9 \mathrm{c} 2$ cells recovered from a hypoxic condition to a normal oxygen status after cholesterol treatment for $48 \mathrm{~h}$, and the expression level of HIF-1 $\alpha$ was significantly decreased compared with that of the other groups.

Based on carbohydrate metabolism, we aimed to explain that HO-1 plays a cardioprotective role and improves the cholesterol-induced hypoxic status in H9c2 cells (42). Our results showed that expression levels of tricarboxylic acid (TCA) cycle-related molecules, Aco2, malate MDH2 and PDHE-1 $\beta$, were obviously changed. Of these, Aco 2 catalyzes the conversion of citrate to isocitrate via cis-aconitate in the second step of the TCA cycle (43). Aco2 was significantly decreased in the $\mathrm{H} 9 \mathrm{c} 2$ cells under cholesterol stimulation. $\mathrm{MDH} 2$ catalyzes the reversible oxidation of malate to oxaloacetate, utilizing the NAD/NADH cofactor system in the TCA cycle (44). PDHE-1 $\beta$ is located in the mitochondrial matrix and catalyzes the conversion of pyruvate to acetyl coenzyme A (Acyl-CoA) (45). In the present study, the expression levels of MDH2 and PDHE-1 $\beta$ were significantly increased in the $\mathrm{H} 9 \mathrm{c} 2$ cells treated with cholesterol. We suggest that cholesterol may destroy the balance of the TCA cycle and induce the excessive accumulation of Acyl-CoA by downregulation of Aco2 expression and upregulation of MDH2 and PDHE-1 $\beta$ expression. Otherwise, LDH catalyzes the conversion of L-lactate and NAD to pyruvate and NADH in the final step of anaerobic glycolysis (46). The expression level of LDH was significantly decreased in the H9c2 cells treated with cholesterol. These findings indicate that cholesterol could inhibit the glycolysis and TCA cycle in H9c2 cells.

In addition, hyperlipidemia can cause a vascular inflammation reaction, leading to the occurrence of atherosclerosis. Atherosclerotic plaque blocks blood vessels, resulting in myocardial infarction, stroke and other serious diseases (47). In addition, hyperglycemia also causes an increase in ROS in clinical hypercholesterolemia patients, which generates the oxidative stress response resulting in the abnormal systolic function of cardiomyocytes $(48,49)$. The results of the cardiac ultrasound indicated that the LV systolic score and ejection fraction of WT mice fed a high-fat diet were significantly decreased compared to that of the WT mice fed a normal diet. Meanwhile, the injury level of cardiac function in the $\mathrm{HO}-\mathrm{1}^{+/-}$ mice was significantly increased compared to that in the WT mice fed a high-fat diet. Meanwhile, the Oil Red O staining results also showed that the lipid accumulation phenomenon in cardiac muscle tissues of the $\mathrm{HO}-1^{+/}$mice was more obvious. These findings indicate that $\mathrm{HO}-1$ protects the systolic function of the heart, improves the blood supply of the coronary artery and target organs, and alleviates the occurrence and development of cardiovascular diseases.

\section{Acknowledgements}

This study was supported by grants from the National Natural Science Foundation of China (no. 81570335), the Tianjin Natural Science Foundation (nos. 15ZXJZSY00010 and 12JCYBJC15900), the Opening Funding for Tianjin Key Laboratory of Cardiovascular Remodeling and Target Organ Injury (no. TJC1401) and intramural research grants from Pingjin Hospital (FYM201538).

\section{References}

1. Gozzelino R, Jeney V and Soares MP: Mechanisms of cell protection by heme oxygenase-1. Annu Rev Pharmacol Toxicol 50: 323-354, 2010.

2. Klickovic U, Doberer D, Gouya G, Aschauer S, Weisshaar S, Storka A, Bilban M and Wolzt M: Human pharmacokinetics of high dose oral curcumin and its effect on heme oxygenase-1 expression in healthy male subjects. BioMed Res Int 2014: 458592, 2014.

3. Chau LY: Heme oxygenase-1: Emerging target of cancer therapy. J Biomed Sci 22: 22, 2015.

4. Yen TL, Chen RJ, Jayakumar T, Lu WJ, Hsieh CY, Hsu MJ, Yang $\mathrm{CH}$, Chang CC, Lin YK, Lin KH, et al: Andrographolide stimulates p38 mitogen-activated protein kinase-nuclear factor erythroid-2-related factor 2-heme oxygenase 1 signaling in primary cerebral endothelial cells for definite protection against ischemic stroke in rats. Transl Res 170: 57-72, 2016.

5. Lv H, Yu Z, Zheng Y, Wang L, Qin X, Cheng G and Ci X: Isovitexin exerts anti-inflammatory and anti-oxidant activities on lipopolysaccharide-induced acute lung injury by inhibiting MAPK and NF- $\kappa \mathrm{B}$ and activating $\mathrm{HO}-1 / \mathrm{Nrf} 2$ pathways. Int $\mathrm{J}$ Biol Sci 12: 72-86, 2016.

6. Wang J, Yang H, Hu X, Fu W, Xie J, Zhou X, Xu W and Jiang H: Dobutamine-mediated heme oxygenase-1 induction via PI3K and p38 MAPK inhibits high mobility group box 1 protein release and attenuates rat myocardial ischemia/reperfusion injury in vivo. J Surg Res 183: 509-516, 2013.

7. Yang YC, Lii CK, Wei YL, Li CC, Lu CY, Liu KL and Chen HW: Docosahexaenoic acid inhibition of inflammation is partially via cross-talk between Nrf2/heme oxygenase 1 and IKK/NF- $\kappa \mathrm{B}$ pathways. J Nutr Biochem 24: 204-212, 2013.

8. Zhang L, Gan ZK, Han LN, Wang H, Bai J, Tan GJ, Li XX, Xu YP, Zhou Y, Gong ML, et al: Protective effect of heme oxygenase-1 on Wistar rats with heart failure through the inhibition of inflammation and amelioration of intestinal microcirculation. J Geriatr Cardiol 12: 353-365, 2015.

9. Seo YJ, Lee KT, Rho JR, Choi JH and Phorbaketal A: Phorbaketal A, isolated from the Marine Sponge Phorbas sp., exerts its anti-inflammatory effects via NF- $\kappa B$ inhibition and heme oxygenase-1 activation in lipopolysaccharide-stimulated macrophages. Mar Drugs 13: 7005-7019, 2015.

10. Miele L, Giorgio V, Alberelli MA, De Candia E, Gasbarrini A and Grieco A: Impact of gut microbiota on obesity, diabetes, and cardiovascular disease risk. Curr Cardiol Rep 17: 120, 2015.

11. Guo F and Garvey WT: Cardiometabolic disease risk in metabolically healthy and unhealthy obesity: Stability of metabolic health status in adults. Obesity (Silver Spring) 24: 516-525, 2016.

12. Melgar-Lesmes P, Garcia-Polite F, Del-Rey-Puech P, Rosas E, Dreyfuss JL, Montell E, Vergés J, Edelman ER and Balcells M: Treatment with chondroitin sulfate to modulate inflammation and atherogenesis in obesity. Atherosclerosis 245: 82-87, 2016.

13. Huang ZP, Kataoka M, Chen J, Wu G, Ding J, Nie M, Lin Z, Liu J, Hu X, Ma L, et al: Cardiomyocyte-enriched protein CIP protects against pathophysiological stresses and regulates cardiac homeostasis. J Clin Invest 125: 4122-4134, 2015.

14. Shimizu I, Yoshida Y and Minamino T: Maintenance of subcutaneous fat homeostasis improves systemic metabolic dysfunction in obesity. Diabetes 64: 3984-3986, 2015.

15. Li X, Ren Y, Sorokin V, Poh KK, Ho HH, Lee CN, de Kleijn D, Lim SK, Tam JP and Sze SK: Quantitative profiling of the rat heart myoblast secretome reveals differential responses to hypoxia and re-oxygenation stress. J Proteomics 98: 138-149, 2014.

16. Schumacher A, Wafula PO, Teles A, El-Mousleh T, Linzke N, Zenclussen ML, Langwisch S, Heinze K, Wollenberg I, Casalis PA, et al: Blockage of heme oxygenase-1 abrogates the protective effect of regulatory $\mathrm{T}$ cells on murine pregnancy and promotes the maturation of dendritic cells. PLoS One 7: e42301, 2012.

17. Das S, Datta A, Bagchi C, Chakraborty S, Mitra A and Tripathi SK: A comparative study of lipid-lowering effects of guggul and atorvastatin monotherapy in comparison to their combination in high cholesterol diet-induced hyperlipidemia in rabbits. J Diet Suppl 13: 495-504, 2016.

18. López-Rosas I, Marchat LA, Olvera BG, Guillen N, Weber C, Hernández de la Cruz O, Ruíz-García E, Astudillo-de la Vega $\mathrm{H}$ and López-Camarillo C: Proteomic analysis identifies endoribouclease EhL-PSP and EhRRP41 exosome protein as novel interactors of EhCAF1 deadenylase. J Proteomics 111: 59-73, 2014. 
19. Zhang T, Xie N, He W, Liu R, Lei Y, Chen Y, Tang H, Liu B, Huang $C$ and Wei $Y$ : An integrated proteomics and bioinformatics analyses of hepatitis $\mathrm{B}$ virus $\mathrm{X}$ interacting proteins and identification of a novel interactor apoA-I. J Proteomics 84: 92-105, 2013.

20. Xu Z, Wang F, Fan F, Gu Y, Shan N, Meng X, Cheng S, Liu Y, Wang C, Song Y, et al: Quantitative proteomics reveals that the inhibition of $\mathrm{Na}(+) / \mathrm{K}(+)$-ATPase activity affects S-phase progression leading to a chromosome segregation disorder by attenuating the aurora a function in hepatocellular carcinoma cells. J Proteome Res 14: 4594-4602, 2015.

21. Ramus C, Hovasse A, Marcellin M, Hesse AM, MoutonBarbosa E, Bouyssié D, Vaca S, Carapito C, Chaoui K, Bruley C, et al: Benchmarking quantitative label-free LC-MS data processing workflows using a complex spiked proteomic standard dataset. J Proteomics 132: 51-62, 2016.

22. Dutta M, Subramani E, Taunk K, Gajbhiye A, Seal S, Pendharkar N, Dhali S, Ray CD, Lodh I, Chakravarty B, et al: Investigation of serum proteome alterations in human endometriosis. J Proteomics 114: 182-196, 2015.

23. Li J, Song J, Bi S, Zhou S, Cui J, Liu J and Wu D: Electrochemical estrogen screen method based on the electrochemical behavior of MCF-7 cells. J Hazard Mater 313: 238-243, 2016.

24. Zhan Y, Zhao F, Xie P, Zhong L, Li D, Gai Q, Li L, Wei H, Zhang L and An W: Mechanism of the effect of glycosyltransferase GLT8D2 on fatty liver. Lipids Health Dis 14: 43, 2015.

25. Wang J, Ji J, Song Z, Zhang W, He X, Li F, Zhang C, Guo C, Wang $C$ and Yuan C: Hypocholesterolemic effect of emodin by simultaneous determination of in vitro and in vivo bile salts binding. Fitoterapia 110: 116-122, 2016.

26. Liu F, Tang W, Chen D, Li M, Gao Y, Zheng H and Chen S: Expression of TGF- $\beta 1$ and CTGF is associated with fibrosis of denervated sternocleidomastoid muscles in mice. Tohoku J Exp Med 238: 49-56, 2016

27. Abraham NG and Kappas A: Pharmacological and clinical aspects of heme oxygenase. Pharmacol Rev 60: 79-127, 2008

28. Li X, Ye F, Li L, Chang W, Wu X and Chen J: The role of HO-1 in protection against lead-induced neurotoxicity. Neurotoxicology 52 $1-11,2016$.

29. Gil-Bona A, Parra-Giraldo CM, Hernáez ML, RealesCalderon JA, Solis NV, Filler SG, Monteoliva L and Gil C: Candida albicans cell shaving uncovers new proteins involved in cell wall integrity, yeast to hypha transition, stress response and host-pathogen interaction. J Proteomics 127: 340-351, 2015.

30. Ning W, Song R, Li C, Park E, Mohsenin A, Choi AM and Choi ME: TGF-beta1 stimulates HO-1 via the p38 mitogenactivated protein kinase in A549 pulmonary epithelial cells. Am J Physiol Lung Cell Mol Physiol 283: L1094-L1102, 2002.

31. Zhang JQ, Zhang JQ, Fang LZ, Liu L, Fu WP and Dai LM: Effect of oral N-acetylcysteine on COPD patients with microsatellite polymorphism in the heme oxygenase-1 gene promoter. Drug Des Devel Ther 9: 6379-6387, 2015.

32. Wu MM, Lee CH, Hsu LI, Cheng WF, Lee TC, Wang YH, Chiou HY and Chen CJ; Meei-Maan Wu: Effect of heme oxygenase-1 gene promoter polymorphism on cancer risk by histological subtype: A prospective study in arseniasis-endemic areas in Taiwan. Int J Cancer 138: 1875-1886, 2016.

33. Daenen KE, Martens P and Bammens B: Association of HO-1 (GT)n promoter polymorphism and cardiovascular disease: A reanalysis of the literature. Can J Cardiol 32: 160-168, 2016.

34. Shibata T, Saito S, Kokubu A, Suzuki T, Yamamoto M and Hirohashi S: Global downstream pathway analysis reveals a dependence of oncogenic NF-E2-related factor 2 mutation on the mTOR growth signaling pathway. Cancer Res 70: 9095-9105, 2010.

35. Pang C, Zheng Z, Shi L, Sheng Y, Wei H, Wang Z and Ji L: Caffeic acid prevents acetaminophen-induced liver injury by activating the Keap1-Nrf2 antioxidative defense system. Free Radic Biol Med 91: 236-246, 2016.
36. Kim JH, Park GY, Bang SY, Park SY, Bae SK and Kim Y: Crocin suppresses LPS-stimulated expression of inducible nitric oxide synthase by upregulation of heme oxygenase-1 via calcium/calmodulin-dependent protein kinase 4. Mediators Inflamm 2014: 728709, 2014

37. Cao H, Feng Y, Ning Y, Zhang Z, Li W and Li Q: Edaravone protects rats and human pulmonary alveolar epithelial cells against hyperoxia injury: Heme oxygenase-1 and PI3K/Akt pathway may be involved. Exp Lung Res 41: 404-414, 2015.

38. Barbagallo I, Parenti R, Zappalà A, Vanella L, Tibullo D, Pepe F, Onni T and Li Volti G: Combined inhibition of Hsp90 and heme oxygenase-1 induces apoptosis and endoplasmic reticulum stress in melanoma. Acta Histochem 117: 705-711, 2015.

39. Chen B, Lu Y, Chen Y and Cheng J: The role of Nrf2 in oxidative stress-induced endothelial injuries. J Endocrinol 225: R83-R99, 2015.

40. Akhtar S, Hartmann P, Karshovska E, Rinderknecht FA, Subramanian P, Gremse F, Grommes J, Jacobs M, Kiessling F, Weber C, et al: Endothelial hypoxia-inducible factor-1 $\alpha$ promotes atherosclerosis and monocyte recruitment by upregulating MicroRNA-19a. Hypertension 66: 1220-1226, 2015.

41. Mao X, Wang T, Liu Y, Irwin MG, Ou JS, Liao XL, Gao X, Xu Y, $\mathrm{Ng} \mathrm{KF}$, Vanhoutte PM, et al: $\mathrm{N}$-acetylcysteine and allopurinol confer synergy in attenuating myocardial ischemia injury via restoring $\mathrm{HIF}-1 \alpha / \mathrm{HO}-1$ signaling in diabetic rats. PLoS One 8: e68949, 2013

42. Chang SH, Barbosa-Tessmann I, Chen C, Kilberg MS and Agarwal A: Glucose deprivation induces heme oxygenase-1 gene expression by a pathway independent of the unfolded protein response. J Biol Chem 277: 1933-1940, 2002.

43. Li C, Lönn ME, Xu X, Maghzal GJ, Frazer DM, Thomas SR, Halliwell B, Richardson DR, Anderson GJ and Stocker R: Sustained expression of heme oxygenase-1 alters iron homeostasis in nonerythroid cells. Free Radic Biol Med 53: 366-374, 2012.

44. Menckhoff L, Mielke-Ehret N, Buck F, Vuletić M and Lüthje S: Plasma membrane-associated malate dehydrogenase of maize (Zea mays L.) roots: Native versus recombinant protein. J Proteomics 80: 66-77, 2013.

45. Mitra A, Basak T, Ahmad S, Datta K, Datta R, Sengupta S and Sarkar S: Comparative proteome profiling during cardiac hypertrophy and myocardial infarction reveals altered glucose oxidation by differential activation of pyruvate dehydrogenase E1 component subunit $\beta$. J Mol Biol 427: 2104-2120, 2015.

46. Zaimoku Y, Takahashi W, Iwaki N, Saito C, Yoshida A, Aoki G, Yamaguchi $\mathrm{M}$ and Nakao S: Human herpesvirus-8-unrelated primary effusion lymphoma of the elderly not associated with an increased serum lactate dehydrogenase level: A benign sub-group of effusion lymphoma without chemotherapy. Leuk Lymphoma 57: 1625-1632, 2016.

47. Pechlaner R, Willeit P, Summerer M, Santer P, Egger G, Kronenberg F, Demetz E, Weiss G, Tsimikas S, Witztum JL, et al: Heme oxygenase-1 gene promoter microsatellite polymorphism is associated with progressive atherosclerosis and incident cardiovascular disease. Arterioscler Thromb Vasc Biol 35: 229-236, 2015.

48. Song G, Zong C, Zhang Z, Yu Y, Yao S, Jiao P, Tian H, Zhai L, Zhao H, Tian S, et al: Molecular hydrogen stabilizes atherosclerotic plaque in low-density lipoprotein receptor-knockout mice. Free Radic Biol Med 87: 58-68, 2015.

49. Yang CM, Lin CC and Hsieh HL: High-glucose-derived oxidative stress-dependent heme oxygenase-1 expression from astrocytes contributes to the neuronal apoptosis. Mol Neurobiol 54: 470-483, 2017. 